\title{
MUNDO DAS IMAGENS E \\ Promessas de Verossimilhança
}

\section{Paulo Cezar Konzen ${ }^{1}$}

Embora as fotografias não possam mentir, os mentirosos podem fotografar.

Lewis Hine

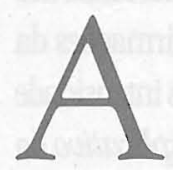

sformas visuais e verbais da cultura veiculada pelos meios eletrônicos de comunicação suplantaram as narrativas sustentadas pela cultura do livro, exigindo novos tipos de abordagem para interpretá-las. A importância de seu estudo reside no fato de que estes meios constituem o principal elemento de socialização, alterando formas de interação social ao substituir a família, a igreja e a escola como juízes a determinar valores, gostos e idéias. Com suas celebridades e imagens atraentes, a televisão, centro destas formas de comunicação, atua decisivamente na constituição de modelos de estilo, moda e comportamento adotados pelos telespectadores.

Neste contexto, com a alteração das percepções de tempo e espaço, a distinção entre imagem e realidade é dificultada ao serem produzidas novas formas de cultura $\mathrm{e}$ novas experiências do presente. Isto porque, quando encaradas como modelos de veracidade, as imagens podem substituir a realidade, principalmente caso sejam compreendidas como cópias exatas desta realidade. A invenção da fotografia no século XIX surge como coroamento da tentativa de se representar o mundo de forma objetiva, tentativa esta que encontra suas origens na pintura renascentista. Na época em que as imagens fotográficas iniciam sua trajetória, compartilha-se a fé em um mundo em que tudo poderia ser descrito e reproduzido em termos de exemplos concretos:

Conhecido como a "era da sciencia", o final do século XIX representa o momento do triunfo de uma certa modernidade que não podia esperar. Catch me who can, dizia 0 cartaz singelamente disposto atrás da primeira locomotiva, como a comprovar que não havia como aguardar ou retardar o progresso (...). Estamos falando, 
portanto, de um momento em que uma certa burguesia industrial, orgulhosa de seu avanço, viu na ciência a possibilidade de expressão de seus mais altos desejos. Tal qual uma revolução industrial que não acaba mais, aqueles homens passavam a domar a natureza a partir de uma miríade de invenções sucessivas. Cada novo invento levava a uma cadeia de inovações, que por sua vez abria perspectivas e projeções inéditas. Dos inventos fundamentais aos mais surpreendentes, das grandes estruturas aos pequenos detalhes, uma cartografia de novidades cobria os olhos desses homens, estupefatos com suas máquinas maravilhosas. ${ }^{2}$

A fotografia é fruto deste "tempo das certezas", tal como foi denominado o século XIX pelo historiador inglês Eric Hobsbawm. Estaé a época em que a submissão à observação do real, do certo e do indubitável repousa como nunca sob a crença na regularidade dos fenômenos naturais: sempre haveria a possibilidade de se comprovar as afirmações da ciência, remetendo-as aos fenômenos naturais de onde emergiram. Com mais intensidade a partir do final do século XIX, portanto, esta concepção em torno do valor explicativo da ciência disseminou raízes junto às áreas humano-culturais, onde assumiu ares de valor interpretativo dos eventos, fenômenos e objetos. Meu interesse na presente análise é mostrar como alguns traços desta concepção permanecem atados à cultura das mídias, principalmente em relatos jornalísticos apresentados pela televisão.

A partir de sua invenção, a fotografia, ao guardar um traço da ação da luz sobre determinados objetos, isentar-se-ia de dar sua interpretação sobre determinado acontecimento, isolando-o (paralisando-o) dos demais e dando provas de sua existência. Para Roland Barthes, a fotografia é vista como o vínculo umbilical que liga o olhar ao corpo da coisa fotografada. ${ }^{3} \mathrm{Na}$ mesma linha de argumentação, Susan Sontag caracteriza a fotografia como vestígio material do objeto fotografado, assim como a pegada é uma marca deixada por alguém ao percorrer um caminho. ${ }^{4}$ Este amálgama entre fotografia e objeto fotografado faz da máquina fotográfica um dispositivo que seria capaz de registrar os acontecimentos objetivamente, já que aquilo que nossos olhos captam é a luz refletida sobre as superfícies, que constituem toda forma de presença material. Esta objetividade será transferida posteriormente para as lentes da câmera de vídeo, de tal maneira que prevalece a idéia de que o que vemos nas telas é captado de maneira absolutamente imparcial. Isto quer dizer que este tipo de argumento está fundado na crença mais ou menos generalizada de que as câmeras não mentem.

\footnotetext{
Costa, A.M.; Schwarcz, L.M. 1890 -1914: no tempo da certezas. São Paulo: Companhia das Letras, 2000. BarTHES, R. A câmara clara: notas sobre a fotografia. Rio de Janeiro: Nova Fronteira, 1984. p. 121.

SonTag, S. Ensaios sobre fotografia. Rio de Janeiro: Arbor, 1981. p. 148.
} 
Esta apreensão objetiva da realidade, captada pelo olhar racional-científico, é contestada por estudiosos - entre eles o mais destacado, pela radicalidade de suas teorias, é Albert Einstein - ao demonstrar que os conceitos de espaço e tempo, bem como os de forma, dimensão, cor etc., são formas de intuição indissociáveis de nossa consciência. ${ }^{5}$ Como resultado, a realidade externa aparece como conjunto de informações conformes à representação produzida em nossas imagens mentais. Com isto, o princípio claro de ordenação dos acontecimentos e de suas provas externas está comprometido devido aos pontos de vista particulares e particularizantes das pessoas responsáveis pela ordenação.

Sendo assim, o que não se pode perder de vista é que a passagem da realidade à sua imagem carrega sempre algum potencial de transformação. Além disso, a captura das imagens será intermediada pelo ponto de vista daquele que maneja a máquina fotográfica ou a câmera de vídeo. Assim como os discursos são convenientes a interesses pessoais, 0 uso destas tecnologias comunicacionais pode ser determinado por interesses de quem as maneja ou controla. Então, as imagens não são menos subjetivas do que o discurso verbal.

A indistinção entre o real e 0 imaginário a partir da emergência do chamado mundo virtual é um dos elementos fundamentais deste conjunto de caracteres. Nesse sentido, o virtual é visto muito menos pelas propriedades técnicas de enunciação das imagens do que como um processo social de desmaterialização do real que implica numa nova forma de apreensão e compreensão do mundo. ${ }^{6}$ As novas tecnologias comunicacionais representariam não o ponto departida, mas o coroamento deste processo: substituição da realidade por sua simulação, como projeto de extensão da realidade. Surge assim um novo relacionamento entre o objeto e sua imagem: ao quebrar a dependência da imagem de um objeto que lhe antecedia, o mundo virtual provoca desdobramentos tecnológicos, psicológicos e ideológicos significativos. Isto porque, tomando-se estas imagens por referência, corre-se o risco de se tomar estapseudo-realidade, mais plástica e mais sedutora que a original, como a própria realidade.

Toda essa mitologia a que as imagens - com a fotografia e posteriormente também com o cinema e a televisão - têm sido associadas, desde as suas origens, está fadada a desaparecer. Isto ocorre porque em função da alta tecnologia que atualmente está presente em todo processo fotográfico e de filmagem - desde os mais sofisticados equipamentos até a manipulação das imagens - a imagem jánão pode atestar a existência de coisa alguma, já não difere da pintura e já não está isenta de subjetividade. Com o

5 Cf. VIRIL10, P. A máquina de visão. Rio de Janeiro: José Olympio, 1994. p. 42.

6 Cf. Virilio, P. Espaço crítico. São Paulo: Editora 34, 1993. 
avanço tecnológico, as imagens já não podem provar muita coisa, legal ou jornalisticamente falando. Isto porque elas perderam seu poder de produzir verossimilhança. ${ }^{7}$ Estes elementos podem ser acionados para analisar a guerra em tempos pós-modernos.

A guerra pode ser definida como violência legitimada em favor da manutenção dos interesses dos Estados-nações. E cada vez mais esta legitimação ocorre diante das câmeras, de forma cada vez mais obscena (no sentido de exposição minuciosa) e acompanhada de perto, no mesmo passo em que os fatos se desenrolam. Portanto, as conseqüências da indistinção entre real e virtual podem ser descritas a partir da instauração de uma nova forma de guerra: a guerra midiática. A Guerra do Golfo evidenciou que, mais do que derrubar o governo iraquiano, os Estados Unidos tiveram como um de seus objetivos centrais mostrar ao mundo que os norte-americanos detêm o poderio militar mais avançado de todos os tempos. Mas este poderio foi ridicularizado com os ataques terroristas de 11 de setembro de 2001, provocando uma sensação incômoda de impotência.

Como extensões de seus telespectadores, emissoras de televisão acompanharam, ao vivo, os ataques a Bagdá e informações instantâneas sobre o desenrolar da guerra espalharam-se por todo o mundo. Aoperação de revanche aos ataques terroristas evidencia que, mais do que a hegemonia na região, importa aos Estados Unidos mostrar ao mundo os milagres da alta tecnologia, o sucesso dos aviões invisíveis, dos mísseis teleguiados, dos sensores infravermelhos, dos satélites espiões, dos lasers e computadores, marcando presença como única potência a deter o monopólio internacional da força. A utilização midiática da guerra, a veiculação da operação cirúrgica, da precisão tecnológica com que os alvos são atingidos, a identificação do campo de batalha como show de luzes e cores, a supressão dos mortos e a pouca importância dada aos protestos contrários à guerra, demonstraram o quanto os militares norte-americanos aprenderam a lição do Vietnã, passando a valerse do poder das imagens para convencer a opinião pública sobre a necessidade da guerra.

0 que fica evidente é que "quanto mais estivermos imersos nas imagens, mais deveremos aprender a desconfiar destas imagens, e evitar de nos deixar absorver pela pseudo-evidência dos sentidos". ${ }^{8}$ Com 0 acesso cada vez maior às informações possibilitado pelos meios de comunicação não éo sujeito que se abre ao mundo. É o mundo que se abre ao indivíduo, que lhe chega sem resistências para satisfazer suas necessidades mais remotas. Nesse sentido, numaépoca de redes de informação mundializadas, a tese de que o volume

Cf. MAснаDO, A. Máquina e imaginário: o desafio das poéticas tecnológicas. São Paulo: Edusp, 1993.

8 Cf. QuÉAu, P. "O tempo do virtual". In: Parente, A. (Org.). Imagem-máquina: a era das tecnologias do virtual. São Paulo: Editora 34, 1993. 
de informações disponíveis e ao alcance de todos representa um estímulo decisivo ao desenvolvimento das potencialidades emancipatórias pode transformar-se em máscara ideológica. Isto porque, nesta perspectiva, confunde-se o excesso de ofertas com a própria realização da democracia, e a descentralização e a flexibilidade com autonomia dos sujeitos. A simples presença de tecnologias comunicacionais não é suficiente para sua utilização transformadora, já que as diferenças sociais, em sua essência, podem ser confirmadas, com força redobrada, a partir destas mesmas tecnologias. Em outras palavras, pode-se sugerir em muitos casos que, diante da impossibilidade de se socializar os lucros, é oferecida, de forma ilusória e compensatória, uma fruição cultural generalizada, com base em uma cultura totalmente desterritorializada, tendo em vista a necessidade de capitalizar signos e referências cada vez mais facilmente inteligíveis para que se tornem facilmente consumíveis.

Para esclarecer este ponto, é preciso advertir que a idéia de máscara ideológica pode ser conjugada no plural: uma visão de mundo qualquer; uma mentira enunciada por uma classe a fim de dominar a outra; o discurso de oposição a esse domínio; uma ilusão necessária criada pelo modo de funcionamento de determinada sociedade; o oposto de ciência; o sinônimo de ciência e tecnologia, quando estas atividades simplesmente reiteram uma realidade imutável. 0 discurso que elogia a proliferação dos meios eletrônicos de comunicação como instrumento a serviço da democracia e da liberdade de expressão parece ordenar alguns destes significados; com mais vigor, aquele que identifica de modo simplório a ciência e a tecnologia com progresso social, político e cultural.

As mudanças técnicas alteraram as relações sociais. Sobre isto não resta dúvida. Mas, o alcance destas mudanças é bastante limitado quando se consideram as enormes diferenças que prevalecem quando se fala das relações com a alteridade, sejam elas entre os países, entre as raças, entre os sexos ou entre as classes. A defesa irrestrita dos progressos verificados na área da comunicação humana não deve ser encarada como conjunto de princípios auto-evidentes que servem para explicar o mundo, sem precisarem eles mesmos de explicação. Caso seja assim, esta defesa poderá integrar aquela família de sentenças que "ajudam a afirmar coisas sobre o mundo sem serem mais vistas elas mesmas como afirmações, quanto mais objetos de discussão e argumentação" . 9 No final do século XX, o predomínio das imagens revela de que maneiras as transformações provocadas pelos meios de comunicação podem alterar as condições discursivas de determinado momento histórico, ou seja, como cada época cria, formata e sedimenta discursos oficiais e como estes discursos são transmitidos, mediados e recebidos socialmente.

9 Bauman, Z. Globalização: as consequiências bumanas. Rio de Janeiro: Jorge Zahar, 1999. p. 14. 
Como afirma Nicolau Sevcenko, "As mudanças históricas ou tecnológicas não são fatalidades, mas, uma vez desencadeadas, estabelecem novos patamares e configurações de fatos, grupos, processos e circunstâncias, exigindo que o pensamento se reformule em adequação aos novos termos para poder interagir com eficácia no novo contexto" ${ }^{10}$ Ler imagens, portanto, é extremamente útil para quem quer descrever por quais meios ocorrerá este processo no século XXI, caso a internet seja confirmada como mais uma ruptura radical de nossas formas de percepção. É claro que não se trata de um mero exercício de futurologia, mas de indicar caminhos percorridos. Caso isto ajude a compreender melhor as relações com as imagens, tanto melhor, já que esta parece ser uma das necessidades urgentes num cenário em que as pessoas se recusam a refletir sobre o tempo que escorre, cada vez mais rapidamente, entre seus dedos

${ }^{10}$ Sevcenko, N. A corrida para o século XXI: no loop da montanha-russa. São Paulo: Companhia das Letras, 2001. 